\title{
Acute respiratory distress syndrome: epidemiology and management approaches
}

This article was published in the following Dove Press journal:

Clinical Epidemiology

13 July 2012

Number of times this article has been viewed

\author{
Allan J Walkey' \\ Ross Summer' \\ $\mathrm{Vu} \mathrm{Ho}$ \\ Philip Alkana ${ }^{2}$ \\ 'The Pulmonary Center, Boston \\ University School of Medicine, Boston, \\ MA, USA; ${ }^{2}$ Asthma Research Center, \\ Brigham and Women's Hospital, \\ Boston, MA, USA
}

\begin{abstract}
Acute lung injury and the more severe acute respiratory distress syndrome represent a spectrum of lung disease characterized by the sudden onset of inflammatory pulmonary edema secondary to myriad local or systemic insults. The present article provides a review of current evidence in the epidemiology and treatment of acute lung injury and acute respiratory distress syndrome, with a focus on significant knowledge gaps that may be addressed through epidemiologic methods.
\end{abstract}

Keywords: acute lung injury, acute respiratory distress syndrome, review, epidemiology

\section{Introduction}

The terms "acute lung injury" (ALI) and "acute respiratory distress syndrome" (ARDS) describe syndromes of acute onset, bilateral, inflammatory pulmonary infiltrates and impaired oxygenation. The first known description of ARDS arrived with the invention of the stethoscope; Laennec described fatal "idiopathic pulmonary edema" in his Treatise on Diseases of the Chest, published in 1821. The wars of the twentieth century provided ample evidence that a myriad of traumatic insults could result in edematous lung injury, 1,2 and various terms (eg, "wet lung," "shock lung," "Da Nang lung") were developed to describe these conditions. However, it was not until 1967 that Ashbaugh et al introduced the term "respiratory distress syndrome" to describe the constellation of acute onset tachypnea, hypoxemia, diffuse pulmonary infiltrates, and loss of lung compliance characterized by high short-term mortality in adults. ${ }^{3}$

The terms ALI and ARDS finally achieved a consensus definition during the American-European Consensus Conference (AECC) on ARDS (Table 1) in 1994, ${ }^{4}$ an accomplishment that allowed coordinated research efforts (eg, initiation of the National Heart, Lung, and Blood Institute's Acute Respiratory Distress Syndrome Network [ARDSNet]) into the epidemiology, pathophysiology, and treatment of ALI/ARDS. In this review, we will discuss the current understanding of pathophysiology, epidemiology, and evidence-based therapeutic approaches for ALI and ARDS.

\section{Definition}

Although the AECC definitions allowed for a concerted ALI/ARDS research effort, the validity of the definition has been criticized. For example, the vague nature of the term "acute," wide intraobserver variation in ascertaining "bilateral radiographic infiltrates," $" 5$ and sensitivity of the $\mathrm{PaO}_{2} / \mathrm{FiO}_{2}$ ratio criteria to small changes in positive end-expiratory pressure (PEEP $)^{6}$ led to the recent revisiting of the AECC definition 
Table I American-European Consensus Conference (AECC) definition of acute lung injury and the Berlin definition of acute respiratory distress syndrome (ARDS)

\begin{tabular}{|c|c|c|}
\hline Characteristic & The AECC definition 1994 & The Berlin definition 2012 \\
\hline Onset & Acute & $\leq 7$ days from the predisposing clinical insult \\
\hline Radiographic abnormality & Bilateral infiltrate on frontal chest radiograph & $\begin{array}{l}\text { Bilateral opacities on radiograph or computed } \\
\text { tomography scan not fully explained by effusion, } \\
\text { atelectasis, or nodules }\end{array}$ \\
\hline $\begin{array}{l}\text { Noncardiogenic source } \\
\text { of pulmonary edema }\end{array}$ & $\begin{array}{l}\text { No clinical evidence of elevated left atrial pressure, } \\
\text { or, a pulmonary capillary wedge pressure }<18 \mathrm{mmHg}\end{array}$ & $\begin{array}{l}\text { Respiratory failure not fully explained by } \\
\text { cardiogenic pulmonary edema or volume overload }\end{array}$ \\
\hline Oxygenation & $\begin{array}{l}\mathrm{PaO}_{2} / \mathrm{FiO}_{2} \text { ratio } \\
\text { Acute lung injury: } \leq 300 \\
\text { Acute respiratory distress syndrome: } \leq 200\end{array}$ & $\begin{array}{l}\mathrm{PaO}_{2} / \mathrm{FiO}_{2} \text { ratio with } \geq 5 \mathrm{~cm} \mathrm{H} \mathrm{H}_{2} \mathrm{O} \text { positive } \\
\text { end-expiratory pressure (PEEP) } \\
\text { Mild ARDS: } 20 \mathrm{I}-300 \\
\text { Moderate ARDS: } 10 \mathrm{I}-200 \\
\text { Severe ARDS: }<100\end{array}$ \\
\hline Predisposing condition & Not specified & $\begin{array}{l}\text { If none identified, then need to rule out cardiogenic } \\
\text { edema with additional data (eg, echocardiography) }\end{array}$ \\
\hline
\end{tabular}

and drafting of the Berlin definition of ARDS ${ }^{7}$ (Table 1). The Berlin criteria were unique in that they were iteratively drafted and then empirically evaluated in order to provide a definition that would be feasible, reliable, and prognostic. Major changes to the AECC definition included: (1) elimination of the term "acute lung injury" as the umbrella term and replacing it with three levels of ARDS severity based on $\mathrm{PaO}_{2} / \mathrm{FiO}_{2}$ measured with at least $5 \mathrm{~cm} \mathrm{H}_{2} \mathrm{O}$ of applied PEEP, (2) defining "acute" as $\leq 7$ days from the predisposing clinical insult, and (3) eliminating pulmonary wedge pressure cutoff values that discriminate ARDS from cardiogenic edema. The Berlin criteria provide a slight improvement in predictive ability for mortality (area under the curve [AUC] 0.577) when compared to the AECC (0.536). In the following review, we will use the Berlin terminology when referring to different subdivisions of $\mathrm{PaO}_{2} / \mathrm{FiO}_{2}$ severity, where applicable.

\section{Pathophysiology}

The pathology of ARDS may progress through three overlapping stages: exudative, proliferative, and fibrotic., Direct or indirect lung insults (Table 2) initiate the exudative phase. This phase is the acute inflammatory stage of ARDS, typified by release of proinflammatory cytokines, influx of neutrophils, and impaired endothelial cell barrier function. Respiratory failure during the exudative phase is attributed to accumulation of protein-rich fluid in distal airspaces and to decreased surfactant production by type II epithelial cells. These early events are followed by the proliferative phase, which develops 2-7 days after initiation of lung injury. This phase is characterized by the proliferation of type 2 pneumocytes, early fibrotic changes, and myointimal thickening of the alveolar capillaries. ${ }^{8,10}$ In some individuals, the proliferative phase progresses to a fibrotic stage that is associated with increased collagen deposition, a prolonged period of ventilation-perfusion mismatching, and diminished compliance of the lung. As evident, the clinical syndrome of ARDS results in multiple pathophysiological changes causing severe respiratory dysfunction.

\section{Epidemiology}

\section{Prevalence and incidence}

Cross-sectional studies demonstrate that patients with ARDS represent approximately $5 \%$ of hospitalized, mechanically ventilated patients. ${ }^{11}$ Most studies have shown that rates of mild ARDS $\left(\mathrm{PaO}_{2} / \mathrm{FiO}_{2} 200-300\right)$ represent only $25 \%$ of patients with ARDS, with approximately $75 \%$ of patients having moderate or severe ARDS. ${ }^{7,12}$ However, approximately one-third of patients with initially mild ARDS will later progress to moderate or severe disease; identification of factors associated with progression of mild ARDS requires further study. The incidence of ARDS varies widely. For example, estimates from prospective US cohort studies using the AECC definition range from $64.2^{13}$ to $78.9^{12}$ cases $/ 100,000$ person-years, whereas estimates from Northern Europe (17 cases/100,000), ${ }^{14}$ Spain (7.2 cases/100,000), ${ }^{15}$ and Australia/New Zealand (34 cases $/ 100,000)^{16}$ have shown substantially lower rates. Rea-

Table 2 Predisposing conditions associated with the acute respiratory distress syndrome

\begin{tabular}{ll}
\hline Direct lung injury & Indirect lung injury \\
\hline Pneumonia & Severe sepsis \\
Aspiration of gastric contents & Blood transfusion \\
Lung contusion & Trauma \\
Toxic inhalation & Cardiopulmonary bypass \\
Near-drowning & Pancreatitis \\
\hline
\end{tabular}


sons for the large variation in ARDS incidence are unclear, and may include major differences in demographics and healthcare delivery systems. ${ }^{15}$ The challenges of recognizing ARDS in administrative data ${ }^{17,18}$ - which requires identification by the clinician, ${ }^{19}$ notation in the chart, and subsequent coding by an administrator - have limited the evaluation of temporal trends and ARDS incidence over larger populationbased samples. Improving the accuracy of ARDS recognition in administrative data represents fertile opportunity for further study.

\section{Risk factors}

A number of single-center prospective cohort studies that enrolled patients at risk for ARDS have identified risk factors for the development of ARDS. Nonmodifiable risk factors for ARDS include a history of alcohol abuse (odds ratio [OR] 2.8), ${ }^{20}$ obesity (OR 1.2 per standard deviation increase in body mass index), and admission severity of illness (OR 2.1 for Acute Physiology and Chronic Health Evaluation [APACHE] II > 16). ${ }^{20}$ Prospective studies have shown either no association ${ }^{20}$ or a protective association ${ }^{21,22}$ between older age and ARDS development. Potentially modifiable risk factors for ARDS include increased use of red blood cell transfusion (OR 1.5 per unit), ${ }^{23}$ admission hypoproteinemia (OR 2.8 for each decline of $2 \mathrm{~g} / \mathrm{dL}$ of admission total protein), ${ }^{22}$ failure to achieve resuscitation goals within 6 hours of septic shock onset (OR 3.5), and failure to provide adequate antibiotics within 3 hours of septic shock (OR 2.4). ${ }^{24}$ Interestingly, patients with diabetes have approximately half the risk for developing ARDS as at-risk patients without diabetes. ${ }^{25}$ Determining mechanisms for these risk factors may allow for the development of therapies that prevent ARDS.

Gajic et al have consolidated prior ARDS risk-factor data in order to develop and validate an acute lung injury prediction score (LIPS). ${ }^{26}$ The multicenter LIPS study prospectively observed 5992 patients admitted with a predisposing condition for ARDS (shock, sepsis, pneumonia, pancreatitis, high-risk trauma, or high-risk surgery). Approximately $10 \%$ of at-risk patients developed ARDS, though incidence varied greatly with predisposing condition (from $2.7 \%$ of patients with pancreatitis to $27 \%$ of patients with smoke inhalation). Table 3 demonstrates factors associated with development of ARDS in the LIPS multivariable-adjusted model. The optimal LIPS score cutoff (AUC 0.8) predicted ARDS with only fair sensitivity (69\%) and specificity (78\%), demonstrating the difficulty of predicting ARDS in at-risk patients.
Table 3 Multivariable-adjusted predisposing conditions and clinical risk factors for acute lung injury (Lung Injury Prediction Study) ${ }^{28}$

\begin{tabular}{ll}
\hline Predisposing conditions & $\begin{array}{l}\text { Proportion of patients } \\
\text { with condition who } \\
\text { develop ARDS }\end{array}$ \\
\hline Shock & $18 \%$ \\
Aspiration & $17 \%$ \\
Aortic surgery & $17 \%$ \\
Emergency surgery & $17 \%$ \\
Cardiac surgery & $10 \%$ \\
Acute abdomen & $9 \%$ \\
Traumatic brain injury & $9 \%$ \\
Pneumonia & $8 \%$ \\
Risk modifiers & Odds ratio for developing \\
& ARDS \\
\hline Obesity (body mass index $>30$ ) & 1.75 \\
Diabetes (only in sepsis; associated & 0.55 \\
with decreased risk) & \\
Hypoalbuminemia & 1.58 \\
FIO $>0.35$ & 2.77 \\
pH $<7.35$ & 1.73 \\
Tachypnea (respiratory rate $>30)$ & 1.99
\end{tabular}

Abbreviation: ARDS, acute respiratory distress syndrome.

\section{Mortality}

ARDS is associated with a hospital mortality of approximately $40 \% .{ }^{12,15}$ Mortality varies according to severity of oxygenation deficit. In the Berlin definition clinical study cohort, mortality was $27 \%$ (95\% confidence interval [CI] 24\%-30\%) in patients with mild ARDS $\left(\mathrm{PaO}_{2} / \mathrm{FIO}_{2} 201-300\right), 32 \%$ (95\% CI 29\%-34\%) in those with moderate ARDS $\left(\mathrm{PaO}_{2} /\right.$ $\mathrm{FIO}_{2}$ 101-200), and 45\% (95\% CI 42\%-48\%) in patients with severe ARDS. ${ }^{7}$ Although worsening oxygenation is a risk factor for ARDS mortality, patients generally die from multisystem organ failure or progressive underlying illness; only a minority of ARDS patients (13\%-19\%) die from refractory respiratory failure. ${ }^{15,27}$ Although mortality has declined since two decades ago, ${ }^{28}$ initial progress in reducing ARDS mortality is likely due to increased implementation of a low tidal-volume mechanical ventilation strategy that reduces further lung injury, systemic inflammation, and subsequent multisystem organ failure. ${ }^{29-31}$ However, among patients who receive low tidal-volume ventilation, mortality rates remain unchanged..$^{30,31}$ Thus, additional treatments for ARDS are sorely needed.

Because of the high mortality and substantial variability in outcomes in patients with ARDS, identification of risk factors for mortality are important to determine prognosis and guide clinical decision-making. In line with observations that mortality in ARDS is generally due to multiple-organ system failure, the best-performing deter- 
minants of prognosis in ARDS are age, severity of disease indices (eg, APACHE scores), ${ }^{32,23}$ and predisposing conditions for ARDS. For example, trauma-induced ARDS has a much more favorable prognosis (approximately $10 \%$ mortality) than other conditions. ${ }^{28,33}$ Clinical risk factors for ARDS mortality include poor oxygenation ${ }^{7,32}$ and poor lung compliance, ${ }^{30}$ although the Berlin ARDS Definition Task Force did not find that lung compliance added significant predictive value over oxygenation alone. ${ }^{7}$ Other predictors of ARDS mortality include pulmonary vascular dysfunction, ${ }^{34}$ lack of temporal improvement in dead-space fraction, ${ }^{35}$ lung compliance, ${ }^{36}$ oxygenation, or shock. ${ }^{37}$

\section{Life after ARDS}

Given the severity of lung-tissue destruction in patients with ARDS, clinicians generally accepted that severe, longterm pulmonary insufficiency was an inevitable outcome for survivors of ARDS. Recent epidemiological studies suggest this is not true. In fact, these studies indicate that lung function in survivors approaches prebaseline levels in the majority of patients within 1 year. ${ }^{38}$ However, ARDS does exact a significant long-term toll on survivors. For example, many patients with ARDS develop long-term neuromuscular, cognitive, and psychological symptoms. Moreover, survivors utilize increased health services after hospital discharge; ARDS has been shown to be one of the most common reasons for admission to a long-term ventilator rehabilitation unit. ${ }^{39}$

\section{Diagnosis}

The diagnosis of ARDS is often clinically challenging because of nonspecific features of this condition. Highlighting the difficulty of ARDS diagnosis, Ferguson et al identified that only $48 \%$ of patients with autopsy-proven ARDS had a diagnosis of ARDS noted in their charts. ${ }^{19}$ ARDS mimics include cardiogenic pulmonary edema, acute eosinophilic pneumonia, acute interstitial pneumonitis, cryptogenic organizing pneumonia, and diffuse alveolar hemorrhage. To differentiate these conditions from ARDS, various diagnostic modalities are utilized, such as sophisticated chest-imaging studies, echocardiography, right-heart catheterization, and bronchoscopy. Lung biopsy has been reported to change management in $60 \%-80 \%$ of select cases in which the diagnosis of ARDS remains uncertain, ${ }^{40-42}$ though whether outcomes are improved through biopsytriggered management change is less clear. Importantly, lung biopsy is reserved for a minority of patients in experienced centers because of its high rate of severe complications $(10 \%)$ in critically ill patients.

\section{Therapeutic strategies}

Therapeutic strategies for ARDS focus upon treating the underlying etiology and providing supportive care that reduces the progression of lung injury. Our algorithm for an evidenced-based approach to ARDS is shown in Figure 1.

\section{Mechanical ventilation}

Most patients with ARDS develop respiratory failure severe enough to require mechanical ventilatory support. Although often a life-saving intervention, respiratory support with a mechanical ventilator is a double-edged sword that can also exacerbate lung injury. Because ARDS is not a homogeneous process, ${ }^{43}$ a disproportional amount of tidal volume during mechanical ventilation is delivered to more compliant, less injured regions (the so-called baby lung), causing overstretch injury to previously functional lung. ${ }^{44}$ In addition, mechanical breaths can cause cyclic lung recruitment and collapse, leading to increased shear-stress forces on the gas-exchange units of the lung. ${ }^{44}$ The combined mechanistic forces of overdistension and cyclic recruitment cause ventilator-associated lung injury (VALI), which then produces "biotrauma" from systemic release of inflammatory cytokines. Currently, the primary goal for management of ARDS is the reduction of VALI.

\section{Low tidal-volume ventilation}

Preclinical animal studies suggested that using low-tidal volumes to ventilate injured lungs minimized lung injury. However, the benefit of this approach was not clearly shown until the first ARDSNet trial ("ARMA") compared a low tidal-volume (goal $6 \mathrm{~mL} / \mathrm{kg}$ of ideal body weight) and low plateau-pressure $\left(<30 \mathrm{~cm} \mathrm{H}_{2} \mathrm{O}\right)$ strategy to a "conventional" tidal-volume and plateau-pressure $(12 \mathrm{~mL} / \mathrm{kg}$ per ideal body weight, $<50 \mathrm{~cm} \mathrm{H}_{2} \mathrm{O}$ ) strategy in 861 ARDS patients. ${ }^{29}$ Patients randomized to low tidal volumes/plateau pressures experienced lower 28 -day mortality (31.0\% versus $38.8 \%$; $P=0.007)$. In conjunction with these findings, patients receiving low lung volumes had lower plasma levels of the proinflammatory cytokine interleukin 6 and subsequently developed fewer organ failures. These findings suggested the benefits of low tidal-volume ventilation may relate to its ability to minimize both local and distant tissue injury. In conjunction with additional trials investigating lung-protective mechanical ventilation strategies, ${ }^{45,46}$ 


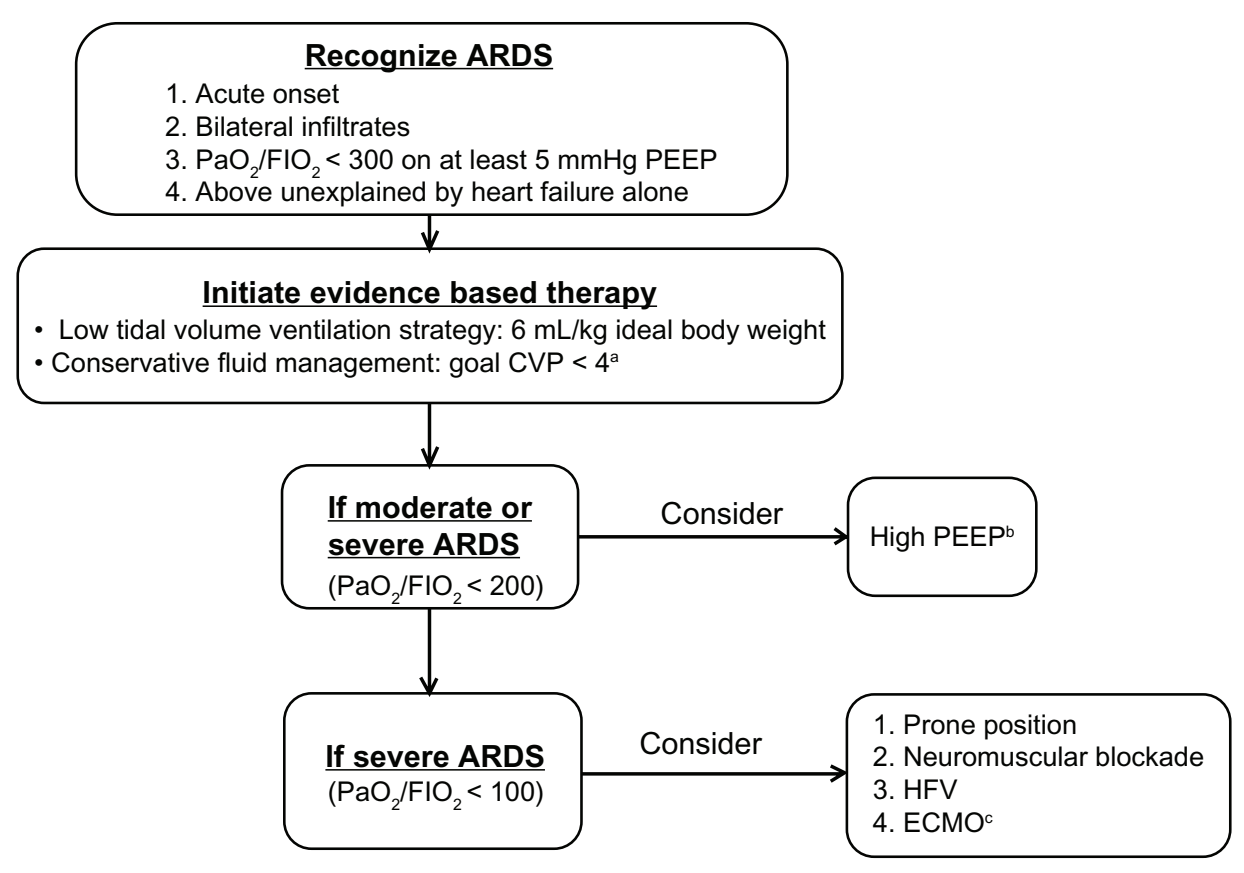

Figure I An evidence-based approach to the management of acute lung injury and acute respiratory distress syndrome. alf urine output $>0.5 \mathrm{~mL} / \mathrm{kg} / \mathrm{hr}$ and mean arterial pressure $>60 \mathrm{mmHg}$ with no vasopressor support. ${ }^{\circ}$ Consider use of ARDSNet.org positive end expiratory pressure (PEEP) table to titrate to PEEP upwards until plateau pressure reaches $30 \mathrm{mmHg}$, or use stress index to titrate PEEP. 'May require transfer to tertiary care facility.

Abbreviations: ARDS, acute respiratory distress syndrome; CVP, central venous pressure; ECMO: extracorporeal membrane oxygenation; HFV, high frequency ventilation kg, kilogram; mL, milliliter.

lung-protective ventilation using low tidal volumes is now the standard of care in treating patients with ARDS. Details of the ARDSNet low tidal-volume strategy can be found at the ardsnet.org website.

\section{Positive end-expiratory pressure}

Another strategy for reducing injury during mechanical ventilation is application of PEEP, which is used to reduce lung collapse at end expiration and improve oxygenation. ${ }^{44,47}$ Like mechanical ventilation itself, PEEP is also a "doubleedged sword" that may overdistend and injure more functional lung, leading to increased barotrauma and hemodynamic compromise. The double-edged sword of high PEEP was highlighted in a meta-analysis of three multicenter trials investigating high PEEP (average $15 \pm 3 \mathrm{~cm} \mathrm{H}_{2} \mathrm{O}$ ) versus low PEEP (average $9 \pm 3 \mathrm{~cm} \mathrm{H}_{2} \mathrm{O}$ ) strategies. ${ }^{48}$ In a predefined subgroup analysis, the authors demonstrated reduced mortality in patients with moderate-severe ARDS $\left(\mathrm{PaO}_{2} / \mathrm{FiO}_{2}<200\right)$ who received high PEEP strategies (34.1\% versus 39.1\%; relative risk [RR] 0.90 [95\% CI, 0.81-1.00], $P=0.049$ ) and a trend towards increased hospital mortality in patients with mild ARDS $\left(\mathrm{PaO}_{2} / \mathrm{FiO}_{2} 200-300\right)$ receiving high-PEEP strategies (27.2\% versus 19.4\%; RR 1.37, 95\% CI, 0.98-1.92; $P=0.07)$. The putative mechanism for the interaction between ARDS severity and the effect of PEEP on mortality is that moderate-to-severe ARDS, and its more severe edema and lung collapse, may respond favorably to higher PEEP, whereas high PEEP may result in overdistention of healthy lung in mild ARDS (Figure 2). What remains unanswered is how to select the optimal PEEP level that assists in lung recruitment without causing lung overdistention. Many approaches have been published, including use of a PEEP-and-FiO ${ }_{2}$ table ${ }^{49}$ use of the inflection points of the lung pressure-volume curve, ${ }^{45}$ titration of PEEP to a maximal plateau pressure of $30 \mathrm{~cm} \mathrm{H} \mathrm{O}_{2},{ }^{50}$ using the "stress index" of the pressure tracing during constant-flow volume-control ventilation to determine tidal hyperinflation versus derecruitment, ${ }^{51}$ and esophageal manometry. ${ }^{52}$ Thus although "higher" PEEP may be beneficial in moderate and severe ARDS, the best method to determine the optimal PEEP level for each patient is unclear and is an important area of further research.

\section{High-frequency ventilation}

High-frequency ventilation takes the concept of low tidalvolume, open-lung ventilation to an extreme, using elevated continuous airway pressure $\left(20-40 \mathrm{~cm} \mathrm{H}_{2} \mathrm{O}\right)$ and very low tidal volumes at very high frequencies $(3-7 \mathrm{~Hz})^{53}$ to oxygenate and ventilate lungs through convective gas motion. ${ }^{54}$ Potential risks of high-frequency ventilation include the need for deep sedation and paralytics, severe respiratory 


\section{A Lung volume $(\mathrm{mL})$}



Airway pressure $\left(\mathrm{cmH}_{2} \mathrm{O}\right)$

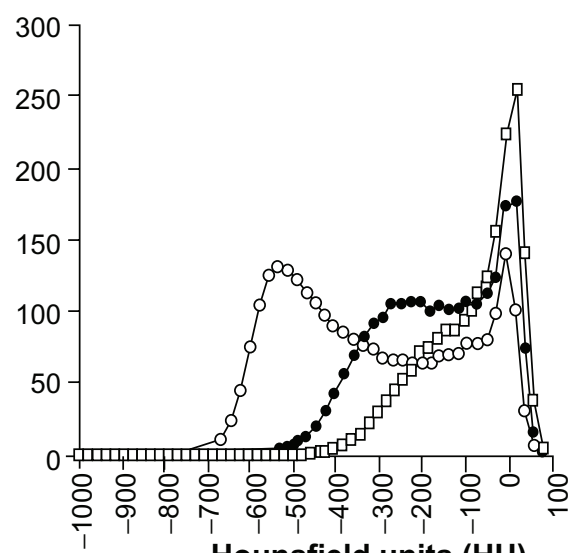

Hounsfield units (HU)

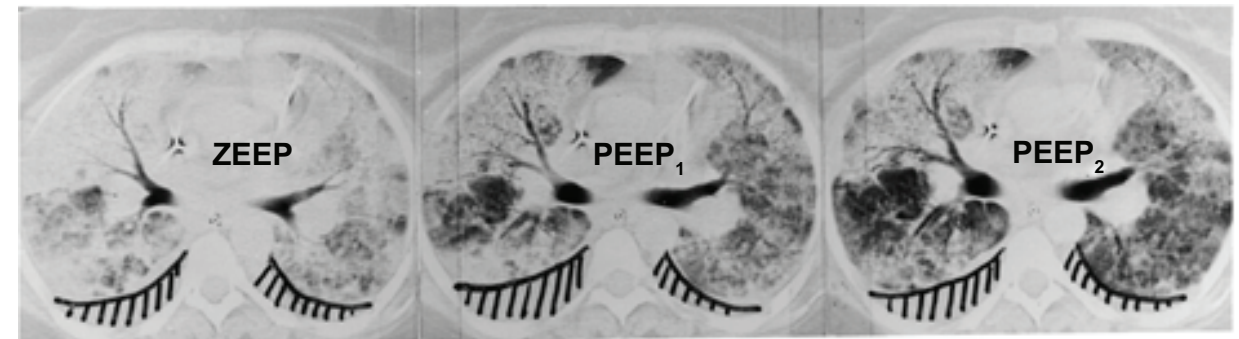

\section{B Lung volume $(\mathrm{mL})$}
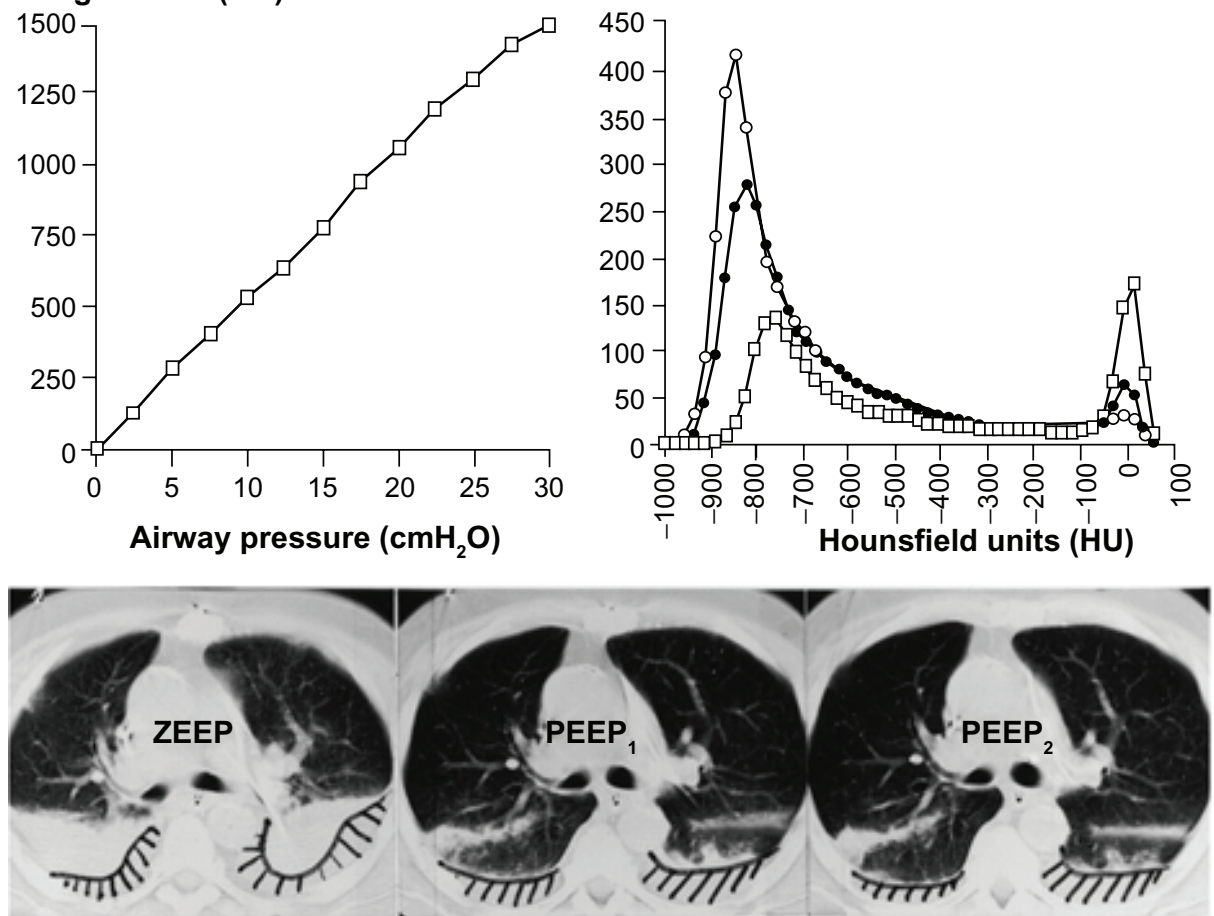

Figure 2 Differential responses to increasing levels of positive end expiratory pressure among patients with ARDS as shown by computed tomography lung images and pressure-volume curves. Total respiratory system $\mathrm{P}-\mathrm{V}$ curve under zero positive end-expiratory pressure (PEEP) (ZEEP) conditions (top left), lung-density histogram analysis (top right), tomographic lung-scan cuts (bottom) under ZEEP (open squares), PEEP, (solid circles), and PEEP ${ }_{2}$ (open circles) conditions of a typical case from the group of patients with $(\mathbf{A})$ and without $(\mathbf{B})$ a lower inflection point.

Notes: (A) A lower inflection point was noted at $10 \mathrm{~cm} \mathrm{H}_{2} \mathrm{O}$, and the patient was ventilated with a PEEP, of $12 \mathrm{~cm} \mathrm{H}_{2} \mathrm{O}$ and a PEEP ${ }_{2}$ of $17 \mathrm{~cm} \mathrm{H}_{2} \mathrm{O}$. Further alveolar recruitment was observed in the linear part of the $\mathrm{P}-\mathrm{V}$ curve, above the lower inflection point, without concomitant alveolar overdistension, as attested to by the absence of lung parenchyma with a computed tomography (CT) number less than -900 Hounsfield units. (B) No lower inflection point was noted, and the patient was ventilated with PEEP , of $10 \mathrm{~cm} \mathrm{H}_{2} \mathrm{O}$ and $\mathrm{PEEP}_{2}$ of $15 \mathrm{~cm} \mathrm{H}_{2} \mathrm{O}$. Alveolar recruitment occurred at the two PEEP levels with simultaneous overdistention, as attested by the increased volume of lung parenchyma with a CT number less than -900 Hounsfield units.

Copyright () 2012, American Thoracic Society Reprinted with permission from Vieira SR, Puybasset L, Lu Q, et al. A scanographic assessment of pulmonary morphology in acute lung injury. Significance of the lower inflection point detected on the lung pressure-volume curve. Am J Respir Crit Care Med. 1999;।59(5 Pt I):16I2-1623. ${ }^{81}$ 
acidosis, and risk of progressive air trapping and barotrauma. A meta-analysis of eight randomized controlled clinical trials comparing high-frequency ventilation to conventional mechanical ventilation in patients with ARDS found that patients randomized to high-frequency ventilation had a $24 \%$ (95\% CI 10\%-40\%, $P<0.001)$ improvement in $\mathrm{PaO}_{2} / \mathrm{FiO}_{2}$ ratio at 24 hours and a reduced 30 -day hospital mortality (RR 0.77 [95\% CI $0.61-0.98], P=0.03] .{ }^{55}$ However, heterogeneity was high among the clinical trials included in the analysis, as two trials were conducted on pediatric patients and the trials used multiple different high-frequency ventilation methods. Importantly, very few adult patients in the comparator groups received mechanical ventilation with the standard-of-care ARDSNet strategy. High-frequency ventilation is currently an experimental alternative to conventional ventilation that likely improves oxygenation; outcome benefits will be evaluated in the multicenter Oscillation for ARDS Treated Early (OSCILLATE) trial (NCT01506401).

\section{Nonmechanical ventilator adjunctive therapies \\ Prone positioning}

Repositioning from supine to prone position alleviates lung compression from mediastinal and abdominal structures, redistributes lung edema to less perfused areas (enhancing oxygenation), and potentially reduces injurious transpulmonary pressures. ${ }^{56}$ In addition, prone position facilitates postural lung drainage and reduces the incidence of ventilator-associated pneumonia. ${ }^{57}$ However, prone positioning is associated with increased risks for adverse events, such as pressure ulcers, endotracheal obstruction, and accidental catheter or tube dislodgement. ${ }^{57}$ The evolution of the evidence in support of prone ventilation mirrors that of high PEEP. Despite improvement in oxygenation with prone ventilation in patients with ARDS, individual multicenter trials have not shown a mortality benefit. However, a meta-analysis and systemic review of ten trials with a cumulative enrollment of 1867 ARDS patients demonstrated an improvement in mortality (RR 0.84 [95\% CI 0.74-0.96], $P=0.01$ ) with prone ventilation only in patients with severe ARDS. ${ }^{57}$ Since a dedicated clinical trial evaluating prone positioning in severe ARDS may not be feasible, it is reasonable to utilize this approach in patients with severe ARDS.

\section{Inhaled pulmonary vasodilator therapy}

Inhaled pulmonary vasodilators (eg, nitric oxide, prostacyclins) are intended to induce vasodilation of the pulmonary vasculature in ventilated lung in order to improve pulmonary hypertension, ventilation-perfusion matching, and oxygenation. ${ }^{58}$ Despite the putative physiologic benefits of improved oxygenation and reduced pulmonary vascular resistance, inhaled vasodilator trials have failed to show a mortality advantage. In meta-analysis, inhaled nitric oxide showed only transient improvements in oxygenation (13\% [95\% CI $4 \%-23 \%$ ] increase compared to control at 24 hours, $P=0.003$; $4 \%[95 \%$ CI $2 \%-13 \%]$ increase at 72 hours, $P=0.17]) .{ }^{59}$ Further, results demonstrated a trend towards increased mortality (RR 1.10 [95\% CI 0.94-1.30]) and a significant increase in renal dysfunction (RR 1.50 [95\% CI 1.11-2.02]) in patients randomized to receive inhaled nitric oxide. ${ }^{59}$ Based on the lack of evidence in support of this therapy, we do not recommend inhaled vasodilator therapy for ARDS.

\section{Extracorporeal membrane oxygenation (ECMO)}

The process of ECMO for severe ARDS involves the rerouting of blood outside the body to external "lung" membranes that function to oxygenate and remove $\mathrm{CO}_{2}$ from the blood. ECMO assumes the main gas-exchange function in the patient with severely compromised lungs to allow "lung rest" and avoid further VALI. Initiation of ECMO involves anticoagulation and the surgical placement of one or two large-bore (21-30 Fr) catheters that pump blood through the "lung" membranes. Early ECMO trials failed to show mortality benefit in the treatment of ARDS. ${ }^{60}$ However, interest in ECMO has been revived by results of the randomized Conventional Ventilation or ECMO for Severe Adult Respiratory failure (CESAR) trial, which showed a reduction in the primary outcome of death or severe disability at 6 months $(37 \%$ versus $53 \%$; RR 0.69 [95\% CI 0.05-0.97], $P=0.03$ ) for patients referred for consideration of ECMO therapy. ${ }^{61}$ However, results of CESAR are confounded by the question of whether the benefit in the "consideration for ECMO" arm was the result of ECMO (used in only $75 \%$ of randomized patients) or due to greater use of a lung-protective ventilation strategy in the ECMO referral center. Due to the high risk of hemorrhage (54\%) - including intracranial hemorrhage in $9 \%$ of patients - ECMO is contraindicated in patients with conditions precluding anticoagulation. ${ }^{62}$ In addition, any potential benefit of ECMO likely wanes after ARDS duration of more than 7 days. ${ }^{62}$ However, in patients with early and severe ARDS without contraindication, transfer to a specialized center for consideration of ECMO may be a reasonable approach.

\section{Corticosteroid therapy}

Because inflammation is thought to be a primary driver of lung injury, there has been considerable interest in 
using anti-inflammatory medications to treat ARDS. Thus far, trials of anti-inflammatory drugs have failed to show significant benefit. The most studied anti-inflammatory medication in ARDS - corticosteroids - warrants more detailed discussion. Trials of short-burst (eg, 24-48 hours), high-dose corticosteroids (eg, methylprednisolone $30 \mathrm{mg}$ / $\mathrm{kg}$ every 6 hours) showed that corticosteroids neither reduced ARDS incidence (OR 1.55, 95\% CI 0.58-4.05) (33 $^{33}$ nor mortality (OR 0.75 [95\% CI $0.41-1.57]$ ). ${ }^{64}$ More controversy exists for low-dose corticosteroids $(0.5-1 \mathrm{mg} / \mathrm{kg} /$ day methylprednisolone). ARDSNet enrolled patients with unresolved ARDS for $>7$ days and found no mortality advantage over placebo (29.2\% versus $28.6 \%) .{ }^{65}$ Subgroup analysis showed that patients receiving methylprednisolone therapy 14 days after diagnosis of ARDS actually experienced increased mortality compared to placebo. The ARDSNet results differ from those of Meduri et al, who found decreased ICU mortality and a trend to decreased hospital mortality (24\% versus $43 \%, P=0.07$ ) in patients randomized to a 28-day continuous-infusion methylprednisolone taper (from $1 \mathrm{mg} / \mathrm{kg} /$ day to $0.125 \mathrm{mg} / \mathrm{kg} /$ day).${ }^{66}$ However, Meduri et al did not specify sample-size goals or stopping rules, did not utilize alpha spending for multiple interim analyses, and allowed crossover of placebo "nonresponders" to corticosteroids after 9 days. Thus, it is possible that the trial showed increased mortality from late initiation of corticosteroids in the placebo-arm group (as per results of the ARDSNet trial), ${ }^{65}$ rather than decreased mortality from early corticosteroids. Meta-analyses of ARDS corticosteroid trials have similarly shown a lack of significant benefit. ${ }^{63,67}$ Given the absence of convincing evidence regarding benefits, we do not routinely use corticosteroids for prevention or treatment of ARDS.

\section{Neuromuscular blocking agents}

Neuromuscular blocking medications are used to induce paralysis and decrease patient-ventilator dysynchrony. Studies investigating the potential benefit of short-term neuromuscular blocking agents in early ARDS have been promising. ${ }^{68}$ Papazian et al randomized 340 patients with ARDS $\left(\mathrm{PaO}_{2} /\right.$ $\mathrm{FiO}_{2}<150$ ) to a 48-hour infusion of cisatracurium versus placebo and found a significant reduction in adjusted 90-day mortality (RR 0.68 [95\% CI $0.48-0.98$ ], $P=0.04$ ) and trend toward a reduction of the crude 90 -day mortality (31.6\% versus $40.7 \% ; P=0.08)$. The study did not find increased development of muscle weakness with short-term cisatracurium infusion compared to placebo. Putative benefits of neuromuscular blockade include reduction in injurious transpulmonary pressures from improved patient-ventilator synchrony ${ }^{68}$ and immunomodulatory properties. ${ }^{69}$ Shortterm, early neuromuscular blockade appears to be a safe and potentially beneficial strategy for patients with severe ARDS.

\section{Fluid management}

AlthoughARDS is defined by the presence of "noncardiogenic" pulmonary edema, $30 \%$ of patients identified clinically as having ARDS have pulmonary artery occlusion pressures greater than $18 \mathrm{mmHg} .{ }^{70}$ Even in patients without elevated cardiac filling pressure, reducing hydrostatic forces has the potential to improve ARDS outcomes. The ARDSNet Fluid and Catheter Treatment Trial investigated the effect of fluid management and hemodynamic monitoring strategies. Although a significant difference in 60-day mortality was not achieved (conservative fluid $25.5 \%$ versus liberal fluid $28.4 \%, P=0.60$ ), patients receiving a conservative fluid approach had decreased duration of mechanical ventilation and improved lung function, without increased adverse events. ${ }^{70}$ Therefore, a conservative fluid approach with a goal central venous pressure of $4 \mathrm{~mm} \mathrm{Hg}$ for patients with adequate urine output $(>0.5 \mathrm{cc} / \mathrm{kg} /$ hour $)$ and effective circulation may facilitate ventilator liberation in patients with ARDS.

\section{Prevention}

Because there are few beneficial treatments, recent studies have focused on identifying ways to prevent the development of ARDS. In a single-center observational study, Yilmaz et al demonstrated that the combination of a low tidal-volume and restrictive blood product-transfusion strategy in mechanically ventilated patients was associated with a reduction in ARDS incidence. ${ }^{71}$ Determann et al randomized at-risk patients to low tidal-volume or conventional tidal-volume strategies and showed reduced ARDS incidence $(2.6 \%$ versus $13.5 \% ; P=0.01)$ and decreased inflammatory cytokines in patients given low tidal volumes. ${ }^{72}$ Remarkably, the use of lower tidal volumes in patients requiring mechanical ventilation may be altering the epidemiology of ARDS. In a single-center study, Li et al demonstrated that the incidence of ARDS declined markedly during the years 2001-08 (from 82.4 to 38.9 per 100,000 person-years). ${ }^{31}$ Notably, the decline in incidence was seen only in hospital-acquired ARDS, rather than ARDS that was present on admission. The authors hypothesized that adoption of restrictive blood transfusion and low tidal-volume ventilation practices may reduce "second hit" factors that increase risk for ARDS. 


\section{Future directions}

Clinical epidemiologists have myriad opportunities to continue to enhance our understanding of ARDS. These include development of methods to reliably identify ARDS in enhanced administrative databases, determination of factors associated with the large variation in incidence of ARDS, and improved characterization of risk modifiers for ARDS development, progression, and mortality. In addition, only a minority of ARDS patients currently receive evidence-based lungprotective ventilation strategies. ${ }^{73-77}$ Studies that investigate strategies to improve implementation of low tidal-volume ventilation are a primary priority for ARDS research. Further, studies that compare effectiveness of alternative ventilator strategies (ie, airway pressure-release ventilation ${ }^{78}$ and variable ventilation $)^{79}$ to the low tidal-volume standard of care are needed. However, even with perfect implementation of lung-protective ventilation, mortality is unacceptably high. Thus, studies that evaluate existing medications with potentially beneficial anti-inflammatory side effects - such as the cholesterol-lowering "statins" (NCT00979121), macrolide antibiotics ${ }^{80}$ and aspirin (NCT01504867) - may find novel treatments for ARDS. Lastly, continued identification of specific ARDS phenotypes that may benefit from certain treatment strategies (eg, high PEEP) may enhance our understanding of the pathophysiology of ARDS.

\section{Conclusion}

The past quarter-century has seen significant progress in our understanding of ARDS. The difficult task of establishing a consensus definition for a syndrome with multiple precipitants allowed for coordinated clinical study that ultimately resulted in a therapeutic approach that improves mortality. Lung-protective ventilation strategies that limit further lung injury, reduce systemic release of inflammatory mediators, and attenuate multiorgan system failure currently represent the standard of care for ARDS. However, our understanding of ARDS epidemiology contains large knowledge gaps, mortality remains unacceptably high, and additional treatments are sorely needed. Clinical epidemiologists will undoubtedly continue to play a large role in enhancing the care of patients with ARDS.

\section{Disclosure}

The authors report no conflicts of interest in this work.

\section{References}

1. Montgomery AB. Early description of ARDS. Chest. 1991;99(1):261-262.

2. Morris MJ. Acute respiratory distress syndrome in combat casualties: military medicine and advances in mechanical ventilation. Mil Med. 2006;171(11):1039-1044.
3. Ashbaugh DG, Bigelow DB, Petty TL, Levine BE. Acute respiratory distress in adults. Lancet. 1967;2(7511):319-323.

4. Bernard GR, Artigas A, Brigham KL, et al. Report of the AmericanEuropean consensus conference on ARDS: definitions, mechanisms, relevant outcomes and clinical trial coordination. The Consensus Committee. Intensive Care Med. 1994;20(3):225-232.

5. Rubenfeld GD, Caldwell E, Granton J, Hudson LD, Matthay MA. Interobserver variability in applying a radiographic definition for ARDS. Chest. 1999;116(5):1347-1353.

6. Villar J, Perez-Mendez L, Lopez J, et al. An early PEEP/FIO2 trial identifies different degrees of lung injury in patients with acute respiratory distress syndrome. Am J Respir Crit Care Med. 2007;176(8): $795-804$.

7. The ARDS Definition Task Force. Acute respiratory distress syndrome: the Berlin definition. JAMA. Epub May 21, 2012.

8. Bellingan GJ. The pulmonary physician in critical care * 6: the pathogenesis of ALI/ARDS. Thorax. 2002;57(6):540-546.

9. Tomashefski JF Jr. Pulmonary pathology of the adult respiratory distress syndrome. Clin Chest Med. 1990;11(4):593-619.

10. Randhawa R, Bellingan G. Acute lung injury. Anaesth Intensive Care Med. 2007;8(11):477-480.

11. Esteban A, Ferguson ND, Meade MO, et al. Evolution of mechanical ventilation in response to clinical research. Am J Respir Crit Care Med. 2008;177(2):170-177.

12. Rubenfeld GD, Caldwell E, Peabody E, et al. Incidence and outcomes of acute lung injury. $N$ Engl J Med. 2005;353(16):1685-1693.

13. Goss CH, Brower RG, Hudson LD, Rubenfeld GD, ARDS Network Incidence of acute lung injury in the united states. Crit Care Med. 2003; 31(6):1607-1611.

14. Luhr OR, Antonsen K, Karlsson M, et al. Incidence and mortality after acute respiratory failure and acute respiratory distress syndrome in Sweden, Denmark, and Iceland. The ARF study group. Am J Respir Crit Care Med. 1999;159(6):1849-1861.

15. Villar J, Blanco J, Anon JM, et al. The ALIEN study: incidence and outcome of acute respiratory distress syndrome in the era of lung protective ventilation. Intensive Care Med. 2011;37(12): 1932-1941

16. Bersten AD, Edibam C, Hunt T, Moran J, Australian and New Zealand Intensive Care Society Clinical Trials Group. Incidence and mortality of acute lung injury and the acute respiratory distress syndrome in three Australian states. Am J Respir Crit Care Med. 2002;165(4): 443-448.

17. Howard AE, Courtney-Shapiro C, Kelso LA, Goltz M, Morris PE. Comparison of 3 methods of detecting acute respiratory distress syndrome: clinical screening, chart review, and diagnostic coding. Am J Crit Care. 2004;13(1):59-64.

18. Iribarren C, Jacobs DR Jr, Sidney S, Gross MD, Eisner MD. Cigarette smoking, alcohol consumption, and risk of ARDS: a 15-year cohort study in a managed care setting. Chest. 2000;117(1):163-168.

19. Ferguson ND, Frutos-Vivar F, Esteban A, et al. Acute respiratory distress syndrome: underrecognition by clinicians and diagnostic accuracy of three clinical definitions. Crit Care Med. 2005;33(10): 2228-2234.

20. Moss M, Bucher B, Moore FA, Moore EE, Parsons PE. The role of chronic alcohol abuse in the development of acute respiratory distress syndrome in adults. JAMA. 1996;275(1):50-54.

21. Gong MN, Bajwa EK, Thompson BT, Christiani DC. Body mass index is associated with the development of acute respiratory distress syndrome. Thorax. 2010;65(1):44-50.

22. Mangialardi RJ, Martin GS, Bernard GR, et al. Hypoproteinemia predicts acute respiratory distress syndrome development, weight gain, and death in patients with sepsis. ibuprofen in sepsis study group. Crit Care Med. 2000;28(9):3137-3145.

23. Gong MN, Thompson BT, Williams P, Pothier L, Boyce PD, Christiani DC. Clinical predictors of and mortality in acute respiratory distress syndrome: potential role of red cell transfusion. Crit Care Med. 2005; 33(6):1191-1198. 
24. Iscimen R, Cartin-Ceba R, Yilmaz M, et al. Risk factors for the development of acute lung injury in patients with septic shock: an observational cohort study. Crit Care Med. 2008;36(5): 1518-1522.

25. Moss M, Guidot DM, Steinberg KP, et al. Diabetic patients have a decreased incidence of acute respiratory distress syndrome. Crit Care Med. 2000;28(7):2187-2192.

26. Gajic O, Dabbagh O, Park PK, et al. Early identification of patients at risk of acute lung injury: Evaluation of lung injury prediction score in a multicenter cohort study. Am J Respir Crit Care Med. 2011;183(4): $462-470$.

27. Stapleton RD, Wang BM, Hudson LD, Rubenfeld GD, Caldwell ES, Steinberg KP. Causes and timing of death in patients with ARDS. Chest. 2005;128(2):525-532.

28. Erickson SE, Martin GS, Davis JL, Matthay MA, Eisner MD, NIH NHLBI ARDS Network. Recent trends in acute lung injury mortality: 1996-2005. Crit Care Med. 2009;37(5):1574-1579.

29. [No authors listed.] Ventilation with lower tidal volumes as compared with traditional tidal volumes for acute lung injury and the acute respiratory distress syndrome. The Acute Respiratory Distress Syndrome Network. N Engl J Med. 2000;342(18):1301-1308.

30. Checkley W, Brower R, Korpak A, Thompson BT, Acute Respiratory Distress Syndrome Network Investigators. Effects of a clinical trial on mechanical ventilation practices in patients with acute lung injury. Am J Respir Crit Care Med. 2008;177(11):1215-1222.

31. Li G, Malinchoc M, Cartin-Ceba R, et al. Eight-year trend of acute respiratory distress syndrome: a population-based study in Olmsted County, Minnesota. Am J Respir Crit Care Med. 2011;183(1):59-66.

32. Monchi M, Bellenfant F, Cariou A, et al. Early predictive factors of survival in the acute respiratory distress syndrome. A multivariate analysis. Am J Respir Crit Care Med. 1998;158(4):1076-1081.

33. Calfee CS, Eisner MD, Ware LB, et al. Trauma-associated lung injury differs clinically and biologically from acute lung injury due to other clinical disorders. Crit Care Med. 2007;35(10):2243-2250.

34. Bull TM, Clark B, McFann K, Moss M, National Institutes of Health/ National Heart, Lung, and Blood Institute ARDS Network. Pulmonary vascular dysfunction is associated with poor outcomes in patients with acute lung injury. Am J Respir Crit Care Med. 2010;182(9): 1123-1128.

35. Siddiki H, Kojicic M, Li G, et al. Bedside quantification of deadspace fraction using routine clinical data in patients with acute lung injury: secondary analysis of two prospective trials. Crit Care. 2010; 14(4):R141.

36. Seeley EJ, McAuley DF, Eisner M, et al. Decreased respiratory system compliance on the sixth day of mechanical ventilation is a predictor of death in patients with established acute lung injury. Respir Res. 2011; $12: 52$.

37. Gajic O, Afessa B, Thompson BT, et al. Prediction of death and prolonged mechanical ventilation in acute lung injury. Crit Care. 2007;11(3):R53

38. Herridge MS, Tansey CM, Matte A, et al. Functional disability 5 years after acute respiratory distress syndrome. E Engl J Med. 2011;364(14): 1293-1304.

39. Mamary AJ, Kondapaneni S, Vance GB, Gaughan JP, Martin UJ, Criner GJ. Survival in patients receiving prolonged ventilation: factors that influence outcome. Clin Med Insights Circ Respir Pulm Med. 2011; 5:17-26.

40. Patel SR, Karmpaliotis D, Ayas NT, et al. The role of open-lung biopsy in ARDS. Chest. 2004;125(1):197-202.

41. Kao KC, Tsai YH, Wu YK, et al. Open lung biopsy in early-stage acute respiratory distress syndrome. Crit Care. 2006;10(4):R106.

42. Baumann HJ, Kluge S, Balke L, et al. Yield and safety of bedside open lung biopsy in mechanically ventilated patients with acute lung injury or acute respiratory distress syndrome. Surgery. 2008;143(3):426-433.

43. Gattinoni L, Mascheroni D, Torresin A, et al. Morphological response to positive end expiratory pressure in acute respiratory failure. Computerized tomography study. Intensive Care Med. 1986;12(3):137-142.
44. Gattinoni L, Pelosi P, Crotti S, Valenza F. Effects of positive endexpiratory pressure on regional distribution of tidal volume and recruitment in adult respiratory distress syndrome. Am J Respir Crit Care Med. 1995;151(6):1807-1814.

45. Amato MB, Barbas CS, Medeiros DM, et al. Effect of a protectiveventilation strategy on mortality in the acute respiratory distress syndrome. N Engl J Med. 1998;338(6):347-354.

46. Villar J, Kacmarek RM, Perez-Mendez L, Aguirre-Jaime A. A high positive end-expiratory pressure, low tidal volume ventilatory strategy improves outcome in persistent acute respiratory distress syndrome: a randomized, controlled trial. Crit Care Med. 2006;34(5): 1311-1318.

47. Gattinoni L, Caironi P, Cressoni M, et al. Lung recruitment in patients with the acute respiratory distress syndrome. $N$ Engl J Med. 2006; 354(17):1775-1786.

48. Briel M, Meade M, Mercat A, et al. Higher vs lower positive end-expiratory pressure in patients with acute lung injury and acute respiratory distress syndrome: systematic review and meta-analysis. JAMA. 2010;303(9):865-873.

49. Brower RG, Lanken PN, MacIntyre N, et al. Higher versus lower positive end-expiratory pressures in patients with the acute respiratory distress syndrome. N Engl J Med. 2004;351(4):327-336.

50. Mercat A, Richard JC, Vielle B, et al. Positive end-expiratory pressure setting in adults with acute lung injury and acute respiratory distress syndrome: a randomized controlled trial. JAMA. 2008;299(6): 646-655.

51. Grasso S, Stripoli T, De Michele M, et al. ARDSnet ventilatory protocol and alveolar hyperinflation: role of positive end-expiratory pressure. Am J Respir Crit Care Med. 2007;176(8):761-767.

52. Talmor D, Sarge T, O'Donnell CR, et al. Esophageal and transpulmonary pressures in acute respiratory failure. Crit Care Med. 2006;34(5): 1389-1394.

53. Stawicki SP, Goyal M, Sarani B. High-frequency oscillatory ventilation (HFOV) and airway pressure release ventilation (APRV): a practical guide. J Intensive Care Med. 2009;24(4):215-229.

54. Pillow JJ. High-frequency oscillatory ventilation: mechanisms of gas exchange and lung mechanics. Crit Care Med. 2005;33(Suppl 3): S135-S141.

55. Sud S, Sud M, Friedrich JO, et al. High frequency oscillation in patients with acute lung injury and acute respiratory distress syndrome (ARDS): systematic review and meta-analysis. BMJ. 2010;340:c2327.

56. Pelosi P, Brazzi L, Gattinoni L. Prone position in acute respiratory distress syndrome. Eur Respir J. 2002;20(4):1017-1028.

57. Sud S, Friedrich JO, Taccone P, et al. Prone ventilation reduces mortality in patients with acute respiratory failure and severe hypoxemia: systematic review and meta-analysis. Intensive Care Med. 2010; 36(4):585-599.

58. Krafft P, Fridrich P, Fitzgerald RD, Koc D, Steltzer H. Effectiveness of nitric oxide inhalation in septic ARDS. Chest. 1996;109(2):486-493.

59. Adhikari NK, Burns KE, Friedrich JO, Granton JT, Cook DJ, Meade MO. Effect of nitric oxide on oxygenation and mortality in acute lung injury: systematic review and meta-analysis. BMJ. 2007;334(7597):779.

60. Zapol WM, Snider MT, Hill JD, et al. Extracorporeal membrane oxygenation in severe acute respiratory failure. A randomized prospective study. JAMA. 1979;242(20):2193-2196.

61. Peek GJ, Mugford M, Tiruvoipati R, et al. Efficacy and economic assessment of conventional ventilatory support versus extracorporeal membrane oxygenation for severe adult respiratory failure (CESAR): a multicentre randomised controlled trial. Lancet. 2009;374(9698): 1351-1363.

62. Kumar A, Zarychanski R, Pinto R, et al. Critically ill patients with 2009 influenza A(H1N1) infection in Canada. JAMA. 2009;302(17): 1872-1879.

63. Peter JV, John P, Graham PL, Moran JL, George IA, Bersten A. Corticosteroids in the prevention and treatment of acute respiratory distress syndrome (ARDS) in adults: meta-analysis. BMJ. 2008;336(7651): 1006-1009. 
64. Bernard GR, Luce JM, Sprung CL, et al. High-dose corticosteroids in patients with the adult respiratory distress syndrome. $N$ Engl J Med. 1987;317(25):1565-1570.

65. Steinberg KP, Hudson LD, Goodman RB, et al. Efficacy and safety of corticosteroids for persistent acute respiratory distress syndrome. N Engl J Med. 2006;354(16):1671-1684.

66. Meduri GU, Golden E, Freire AX, et al. Methylprednisolone infusion in early severe ARDS: results of a randomized controlled trial. Chest. 2007;131(4):954-963.

67. Tang BM, Craig JC, Eslick GD, Seppelt I, McLean AS. Use of corticosteroids in acute lung injury and acute respiratory distress syndrome: a systematic review and meta-analysis. Crit Care Med. 2009;37(5):1594-1603.

68. Papazian L, Forel JM, Gacouin A, et al. Neuromuscular blockers in early acute respiratory distress syndrome. NEngl J Med. 2010;363(12): 1107-1116.

69. Forel JM, Roch A, Marin V, et al. Neuromuscular blocking agents decrease inflammatory response in patients presenting with acute respiratory distress syndrome. Crit Care Med. 2006;34(11):2749-2757.

70. Wiedemann HP, Wheeler AP, Bernard GR, et al. Comparison of two fluid-management strategies in acute lung injury. N Engl J Med. 2006; 354(24):2564-2575.

71. Yilmaz M, Keegan MT, Iscimen R, et al. Toward the prevention of acute lung injury: protocol-guided limitation of large tidal volume ventilation and inappropriate transfusion. Crit Care Med. 2007;35(7):1660-1666; quiz 1667.

72. Determann RM, Royakkers A, Wolthuis EK, et al. Ventilation with lower tidal volumes as compared with conventional tidal volumes for patients without acute lung injury: a preventive randomized controlled trial. Crit Care. 2010;14(1):R1.
73. Walkey AJ, Wiener RS. Risk factors for underuse of lung-protective ventilation in acute lung injury. J Crit Care. 2012;27(3):323. e1-e9.

74. Umoh NJ, Fan E, Mendez-Tellez PA, et al. Patient and intensive care unit organizational factors associated with low tidal volume ventilation in acute lung injury. Crit Care Med. 2008;36(5):1463-1468.

75. Kalhan R, Mikkelsen M, Dedhiya P, et al. Underuse of lung protective ventilation: analysis of potential factors to explain physician behavior. Crit Care Med. 2006;34(2):300-306.

76. Mikkelsen ME, Dedhiya PM, Kalhan R, Gallop RJ, Lanken PN, Fuchs BD. Potential reasons why physicians underuse lung-protective ventilation: a retrospective cohort study using physician documentation. Respir Care. 2008;53(4):455-461.

77. Needham DM, Colantuoni E, Mendez-Tellez PA, et al. Lung protective mechanical ventilation and two year survival in patients with acute lung injury: prospective cohort study. BMJ. 2012;344:e2124.

78. Putensen $\mathrm{C}$, Zech S, Wrigge H, et al. Long-term effects of spontaneous breathing during ventilatory support in patients with acute lung injury. Am J Respir Crit Care Med. 2001;164(1):43-49.

79. Bellardine CL, Hoffman AM, Tsai L, et al. Comparison of variable and conventional ventilation in a sheep saline lavage lung injury model. Crit Care Med. 2006;34(2):439-445.

80. Walkey AJ, Wiener RS. Macrolide antibiotics and survival in patients with acute lung injury. Chest. 2012;141(5):1153-1159.

81. Vieira SR, Puybasset L, Lu Q, et al. A scanographic assessment of pulmonary morphology in acute lung injury. Significance of the lower inflection point detected on the lung pressure-volume curve. Am J Respir Crit Care Med. 1999;159(5 Pt 1):1612-1623.
Clinical Epidemiology

\section{Publish your work in this journal}

Clinical Epidemiology is an international, peer-reviewed, open access journal focusing on disease and drug epidemiology, identification of risk factors and screening procedures to develop optimal preventative initiatives and programs. Specific topics include: diagnosis, prognosis, treatment, screening, prevention, risk factor modification, systematic

\section{Dovepress}

reviews, risk \& safety of medical interventions, epidemiology \& biostatical methods, evaluation of guidelines, translational medicine, health policies \& economic evaluations. The manuscript management system is completely online and includes a very quick and fair peer-review system, which is all easy to use. 